\title{
Effect of Intravenous Ondansetron for Prevention of Spinal Anaesthesia Induced Hypotension during Caesarean Section
}

\author{
Kriti Devkota, ${ }^{1}$ Kiran Adhikari, ${ }^{2}$ Bijay Pradhan, ${ }^{3}$ \\ 'Lecturer, Department of Anaesthesia, College of Medical Sciences, Bharatpur, Chitwan, Nepal ${ }^{2}$ Lecturer, Department of \\ Anaesthesia, Chitwan Medical College, Bharatpur, Chitwan, Nepal ${ }^{3}$ Resident, Department of Anaesthesia College of Medical \\ Sciences, Bharatpur, Chitwan, Nepal
}

\section{ABSTRACT}

\section{Introduction}

Hypotension is one of the most common complications associated with spinal anaesthesia. Maternal hypotension during caesarean section is more dangerous as it can compromise fetal outcome. Serotonin (5-HT3) has been found to induce Bezold Jarisch Reflex (BJR) causing bradycardia and hypotension in background of decreased blood volume. Ondansetron, a serotonin antagonist may play important role in prevention of spinal induced hypotension. The aim of this study is to determine the effect of intravenous ondansetron to prevent spinal induced hypotension during caesarean section.

\section{Methods}

A prospective randomised double blind study was done among singleton parturients scheduled for elective caesarean delivery under spinal anaesthesia from $2^{\text {nd }}$ July 2020 to $31^{\text {st }}$ October 2021 in College of Medical Sciences Teaching Hospital. One hundred and thirty patients were randomised by lottery method into two groups (group $\mathrm{S}$ and group $\mathrm{O}$ ) each with 65 patients to receive either 4 $\mathrm{mg}$ of intravenous (IV) ondansetron diluted in $10 \mathrm{ml}$ of normal saline or $10 \mathrm{ml}$ of normal saline alone. Various haemodynamic parameters like systolic and diastolic blood pressure (SBP/DBP), mean arterial pressure (MAP), heart rate (HR), oxygen saturation $\left(\mathrm{Spo}_{2}\right)$ and vasopressor requirement were compared between the two groups using SPSS 20. Student's $t$ test and chi-square test were used for comparison of parametric and non-parametric data.

\section{Results}

Incidence of hypotension was 28 (43.07\%) in saline group and 11 (16.92\%) in ondansetron group. There were statistically significant differences in SBP, DBP and MAP at three, six, nine twelve, fifteen and eighteen minutes. Incidence of shivering was $15(23.07 \%)$ in ondansetron while 28 $(43.07 \%)$ in saline group which was statistically significant. No other benefit of ondansetron was observed in present study.

\section{Conclusions}

Prophylactic administration of IV ondansetron could significantly reduce the incidence of spinal induced hypotension during caesarean section.

Keywords: Caesarean section; Hypotension; Ondansetron; Spinal anaesthesia

Correspondence: Dr. Kriti Devkota, Lecturer, Department of Anaesthesia, College of Medical Sciences Teaching Hospital. Email: dr.kriti.devkota@gmail.com. Phone: +977-9851215676. 


\section{INTRODUCTION}

Neuraxial block is considered as standard care of anaesthesia for caesarean section as it reduces anaesthesia related maternal morbidity and mortality. ${ }^{1}$ Spinal anaesthesia is safer, quicker and reliable anesthetic option but has its own adverse effects. Bradycardia and hypotension are most commonly encountered side effects with incidence of $13 \%$ and $33 \%$ respectively in non-obstetric population. ${ }^{2}$ In parturients the incidence reaches upto $83 \%$ which can compromise fetal outcome resulting in fetal hypoxia, acidosis and low APGAR scores. ${ }^{2}$ Various techniques like physical methods (leg wrap), vasopressors (ephedrine, phenylephrine) and use of fluids (crystalloids or colloids) have been used for its prevention. ${ }^{3}$

Spinal induced hypotension (SIH) is caused due to sympathetic blockade resulting in decreased systemic vascular resistance whereas bradycardia occur secondary to parasympathetic dominance, increased baroreceptor activity or activation of Bezold Jarisch reflex (BJR). BJR is a triad of bradycardia, hypotension and peripheral vasodilation which arises from stimulation of mechanoreceptors and chemoreceptors located in the left ventricle. ${ }^{4-6}$ Serotonin $(5 \mathrm{HT})$ has been found to trigger this reflex in various animal studies in hypovolemic settings. ${ }^{7-10}$

Aim of this study was to compare the effect of ondansetron, a 5-HT3 antagonist with placebo for attenuation of spinal induced hypotension.

\section{METHODS}

This was a prospective randomised double blind study conducted in the Department of Anaesthesia of College of Medical Sciences, Teaching Hospital (COMS-TH), Chitwan, Nepal. After approval from institutional review committee (Ref. 2020-065), all ASA II singleton parturients undergoing elective caesarean section under spinal anaesthesia from July $2^{\text {nd }}$
2020 to October $31^{\text {st }} 2021$ were taken up for study.

Patients with known contraindication to spinal anaesthesia, allergic to the study drug, patients with comorbidities like pregnancy induced hypertension, gestational diabetes mellitus, coronary artery disease or heart disease, patients taking drugs like selective serotonin receptor inhibitors (SSRIs) and patients converted into general anaesthesia were excluded from our study.

The sample size was calculated based on study conducted by Sahoo et $\mathrm{al}^{11}$ using formula:

$\mathrm{n}=\frac{(\mathrm{z} \alpha+\mathrm{Z} \beta)^{2} \times\left(\mathrm{g} 1^{2}+\sigma 2^{2}\right)}{\left(\mathrm{m}^{1}-\mathrm{m}^{2}\right)^{2}}$

$\mathrm{n}=\frac{(1.96+0.85)^{2} \times\left(11.7^{2}+10.5^{2}\right)}{(88-82.2)^{2}}$

$\mathrm{n}=58$

So, minimum of 58 samples in each group was required. We included 65 parturients in each group of our study.

Pre anesthetic evaluation was done a day before surgery and informed written consent was taken. They were asked for preoperative fasting period of eight hours and brought to pre anesthetic room the other day. An 18G cannula was inserted and Inj.ranitidine 150 $\mathrm{mg}$ and Inj. metoclopramide $10 \mathrm{mg}$ were given intravenously. Ringer's Lactate (RL) 20ml/kg was started to be given for 20 minutes. Folded paper with $\mathrm{O}$ or $\mathrm{S}$ written was kept in a box and parturients were asked to pick one from the box. It was handed over to an anaesthesia assistant who unfolded the paper and checked the group. The anaesthesia assistant not involved in the study noted the group $\mathrm{O}$ and group $\mathrm{S}$ according to the chosen paper and maintained in a register. He then prepared Inj. ondansetron $4 \mathrm{mg}$ diluted in $10 \mathrm{ml}$ of $\mathrm{NS}$ for Group O while $10 \mathrm{ml}$ of normal saline was prepared for group $S$. 
Patient was then taken to the operating room and baseline heart rate (HR), noninvasive blood pressure (NIBP) and oxygen saturation (Spo2) were recorded. Maintenance fluid (RL) was then started at the rate of $100 \mathrm{ml} / \mathrm{hr}$. Anesthesiologist blinded to the prepared drug solution slowly administered $10 \mathrm{ml}$ solution over 10 seconds. After 5 minutes, spinal anaesthesia was performed in L3-L4 or L4 -L5 interspace with 25 G Quincke's spinal needle using $2.2 \mathrm{ml}$ of $0.5 \%$ heavy bupivacaine in sitting position. Patient was then immediately placed in supine position with 15 degree tilt to the left.

HR, SBP, DBP, MAP and oxygen saturation was recorded in individual proforma at the time of spinal anaesthesia and then every three minute interval upto 30 minutes. Level of sensory block was measured at five minute intervals for loss of cold sensation using alcohol swabs till 15 minutes. Surgery was allowed to start once upper sensory level reached T6. Motor block was also assessed at same time interval using the modified Bromage scale. ${ }^{12,13}$

Inj Oxytocin 3 unit bolus over 15 seconds was given to all patients after delivery of the baby. Any additional use of oxytocin was noted. Inj mephentermine $6 \mathrm{mg}$ IV bolus was used to treat hypotension (SBP $<90 \mathrm{~mm} \mathrm{Hg}$ or DBP $<60 \mathrm{~mm} \mathrm{Hg}$ or MAP $<60 \mathrm{~mm}$ of $\mathrm{Hg}$ ) and Inj atropine $0.6 \mathrm{mg}$ for bradycardia (HR $<50$ bpm). Values before use of these drugs were recorded for calculation. Amount of blood loss and occurrence of pain and rigor were also recorded. After completion of surgery, patients were shifted to recovery room and observed for 30 minutes after which they were transferred to post-operative unit.

The recorded data from patient's proforma and register of anesthesia assistant was transferred in MS excel which was later prepared and was analyzed using SPSS 20. Student's t test for parametric data and chi-square test for non-parametric data were performed for comparison.

\section{RESULTS}

One hundred and thirty patients were included in this study, 65 in each group, all of whom completed the study. There was no statistically significant difference among the demographic variables in both groups shown in Table 1 . There was no significant difference in SBP, DBP, MAP, $\mathrm{Spo}_{2}$ and $\mathrm{HR}$ in baseline recording between the groups (Table 1 )

Table 1. Demographic and baseline recording values of two groups

\begin{tabular}{|l|c|c|c|}
\hline & Group O & Group S & p-value \\
\cline { 2 - 4 } & Mean \pm S.D & Mean \pm S.D & 0.163 \\
\hline Age (in years) & $26.86 \pm 4.16$ & $27.88 \pm 4.09$ & 0.241 \\
\hline Height (in cms) & $153.29 \pm 3.14$ & $152.65 \pm 3.12$ & 0.918 \\
\hline Weight (in Kg) & $67.03 \pm 6.54$ & $66.92 \pm 5.29$ & 0.697 \\
\hline Body mass index(BMI) & $28.52 \pm 2.53$ & $28.69 \pm 2.40$ & 0.547 \\
\hline Baseline SBP (mm Hg) & $118.22 \pm 8.75$ & $117.37 \pm 7.17$ & 0.139 \\
\hline Baseline DBP (mm Hg) & $71.89 \pm 8.33$ & $69.80 \pm 7.68$ & 0.147 \\
\hline Baseline MAP (mm Hg) & $82.82 \pm 7.95$ & $80.86 \pm 7.32$ & 0.522 \\
\hline Baseline HR (mm Hg) & $89.62 \pm 11.29$ & $88.45 \pm 9.40$ & 0.558 \\
\hline Baseline Spo (\%) & $98.66 \pm 0.97$ & $98.57 \pm 0.81$ & \\
\hline
\end{tabular}


The incidence of hypotension in the saline group was $43.07 \%$ compared to $16.92 \%$ in ondansetron group. There was statistically significant differences, at three, six and nine minutes, tweleve, fifteen and eighteen minutes in SBP (Figure 1), DBP (Figure 2) and MAP (Figure 3). There were no episodes of bradycardia or significant differences in HR recorded over 30 minutes at three minutes interval in both groups.
A total of $11(16.92 \%)$ patients in ondansetron group and $28(43.07 \%)$ patients in saline group required Inj.mephentermine for correction of hypotension. The use of vasopressor was significantly higher in saline group $(p=0.002)$. (Table 2) Of the 28 patient requiring vasopressor in saline group, eight required once, 15 required twice and five were given three times. In ondansetron group, six patients required once while five patients required vasopressor for two times.
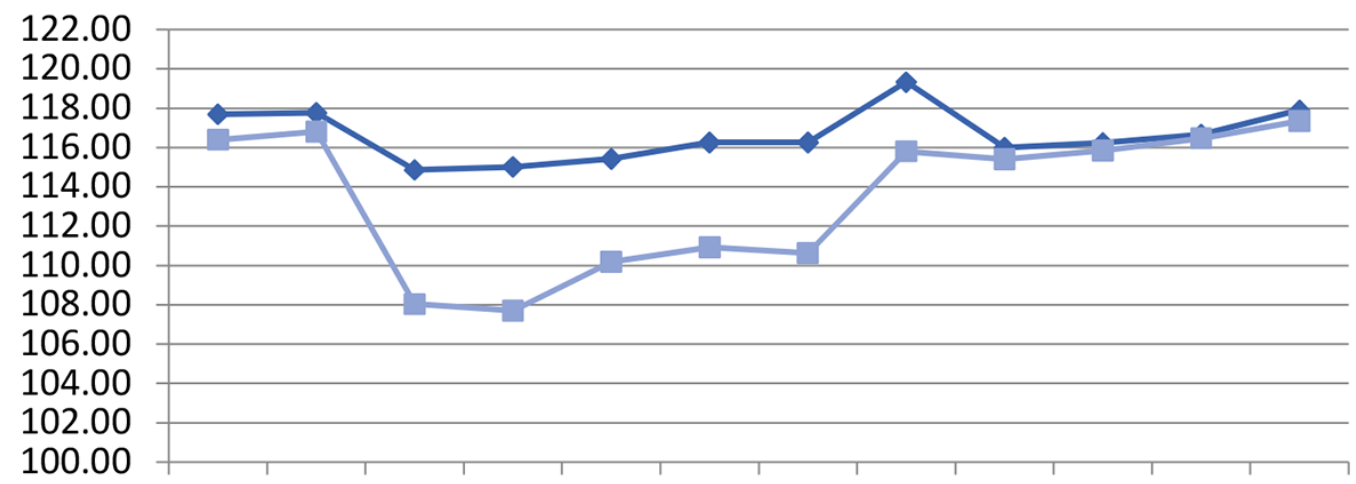

$\multimap$ Ondansetron

100.00

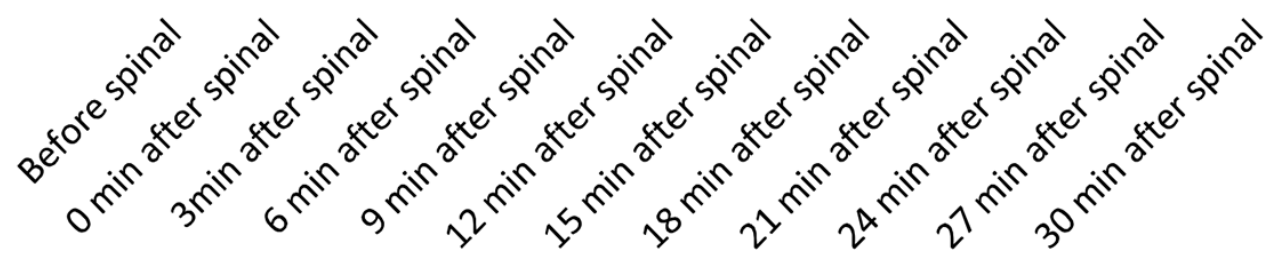

Figure 1. Line diagram showing the mean SBP

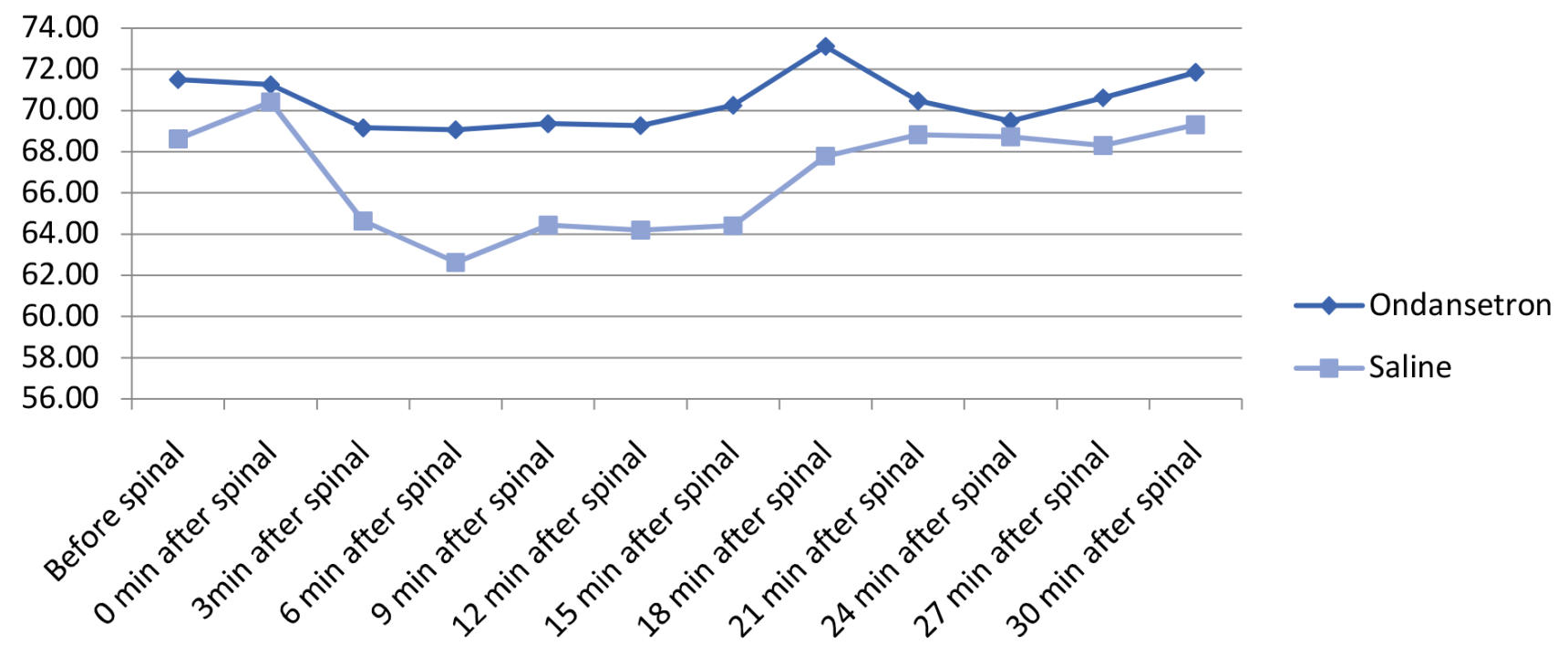

Figure 2. Line diagram showing mean DBP 


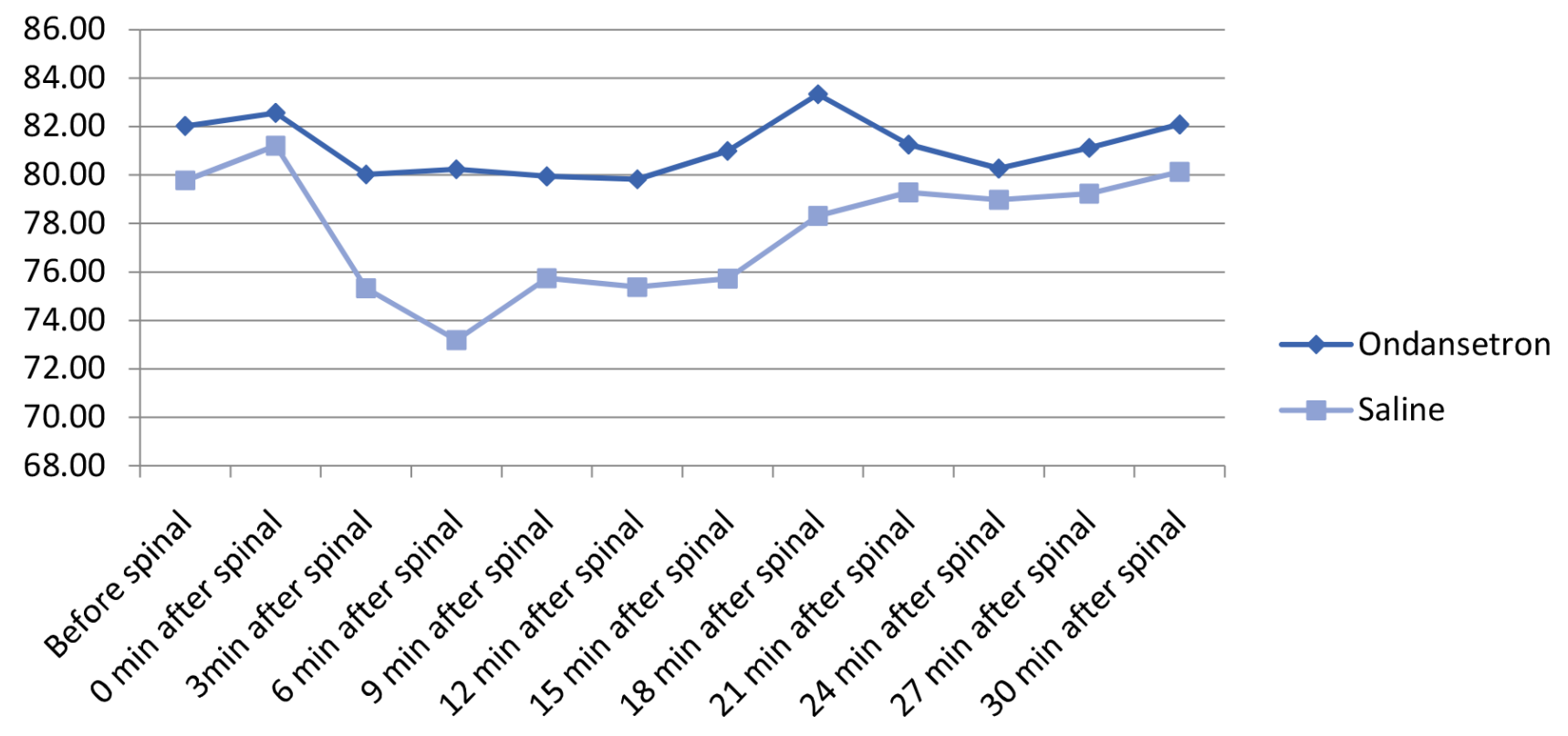

Figure 1. Line diagram showing the mean SBP

Table 2. Use of vasopressor

\begin{tabular}{|c|c|c|c|c|}
\hline Group & \multicolumn{2}{|c|}{ vasopressor } & & \\
\hline & Used & not used & & p value \\
\hline Ondansetron & 11 & 54 & 65 & \\
\hline Saline & 28 & 37 & 65 & $0.002^{*}$ \\
\hline & 39 & 91 & 130 & \\
\hline
\end{tabular}

$28(43.07 \%)$ patients in saline group and 15 $(23.07 \%)$ patients in ondansetron group had shivering which was statistically significant $(p=0.025)$. There were five patients in the saline group who complained of nausea while only two patients in ondansetron group had this complaint. However, this difference was not statistically significant. No patients in both groups had episode of vomiting.

\section{DISCUSSION}

Hypotension during spinal anaesthesia is a frequently occurring event with incidence upto $33 \%$ in non-obstetric population which reaches even higher upto $83 \%$ in parturients. ${ }^{2,4,5}$ It is hazardous for the fetus due to compromise in uteroplacental circulation. So, a number of techniques have been employed for its mitigation. ${ }^{3}$

In the background of hypovolemia, cardiac receptors in the left ventricle get stimulated and induce BJR resulting in vasodilation, hypotension and reflex bradycardia. This response is also believed to be encited by chemoreceptors sensitive to serotonin. Ondansetron, a 5-HT3 antagonist has been found to be effective in attenuation of spinal induced hypotension in various studies done in both obstetric and non-obstetric population. ${ }^{11,14-16}$ We have used intravenous ondansetron $4 \mathrm{mg} 5$ minutes before spinal anaesthesia for elective caesarean section in our study as a measure to prevent hypotension and found it to be effective.

The incidence of hypotension in ondansetron group in present study was $16.92 \%$ while in saline group was $43.07 \%$. Our study showed significantly lower incidence $(p=0.002)$ of hypotension in ondansetron group than that in saline group. Studies done by Khouly et al. ${ }^{17}$ 
and Sahoo et al. ${ }^{11}$ also demonstrated similar results. Both of these studies were done in parturients using similar dose of opioid free heavy bupivacaine comparable to our study $(2$ $\mathrm{ml}$ of $0.5 \%$ heavy bupivacaine).

The use of vasopressor was also significantly higher in saline group in our study. This was relatable to study done by Trabelsi et al. in 80 parturients posted for elective caesarean section $(p<0.001) .{ }^{18}$

Wang et al. ${ }^{19}$ had done a dose dependent study using 4 different doses (2, 4, 6 and $8 \mathrm{mg}$ ) of ondansetron for cesarean deliveries and concluded dose of $4 \mathrm{mg}$ of ondansetron to be optimal for hemodynamic benefit. We also did the present study using $4 \mathrm{mg}$ of ondansetron and showed similar results.

Gomez et al. ${ }^{20}$ had also done similar study using $2 \mathrm{mg}, 4 \mathrm{mg}$ and $8 \mathrm{mg}$ of ondansetron but did not demonstrate reduction in episodes of hypotension in ondansteron group compared with saline group. They had used a height based dose of bupivacaine ( $\mathrm{mg}=$ height in $\mathrm{cm}{ }^{*} 0.06$ ) along with fentanyl 20 micrograms whereas we had used fixed dose of $11 \mathrm{mg}$ bupivacaine for all patients. Personalising individual doses might have resulted in lower incidence of hypotension in their study. They had also used a lower dose of only 1 unit of oxytocin after delivery while we had used bolus of 3 units of oxytocin. This might be a reason for more stable hemodynamics in their study.

No episodes of bradycardia were noted in both the groups of our study. Similar results were produced in study done by Terkawi et al. ${ }^{21}$ but unlike ours, they did not show advantage of ondansetron even in reduction of episodes of hypotension. They had used a larger dose of $15 \mathrm{mg}$ of bupivacaine along with $20 \mathrm{mcg}$ of fentanyl and $100 \mathrm{mcg}$ of preservative free morphine for spinal anaesthesia in their study compared to opioid free $11 \mathrm{mg}$ of bupivacaine used in our study.

Our study also demonstrated beneficial effects of ondansetron for prevention of shivering with incidence of $43.07 \%$ in saline group and $23.07 \%$ in ondansteron group. Studies done by Tatikonda et al. ${ }^{16}$ and Marashi et al. ${ }^{14}$ also demonstrated similar benefit. Both of these studies were done in ceseraen section using 15 $\mathrm{mg}$ of bupivacaine which was higher than the dose used in our study (11 mg). However, they had also demonstrated a significant reduction in use of vasopressors in ondansteron group of their study.

Limitations and recommendation: A small sample size and use of a fixed dose of bupivacaine for all the parturients may be the limitations of our study. We had also used noninvasive blood pressure monitoring in our study which might not be able to reflect exact blood pressure measurement of the patient.

Further studies with larger sample size and use of invasive blood pressure monitoring would help to accurately identify the role of ondansetron in attenuation of spinal induced hypotension in caesarean section.

\section{CONCLUSIONS}

Ondansetron administered at a dose of 4 $\mathrm{mg}$ intravenously before spinal anaesthesia was effective in reducing the incidence of hypotension as well as shivering in pregnant women undergoing caesarean section.

\section{Conflict of interest: Nil}




\section{REFERENCES}

1. Breivik $\mathrm{H}$, Bang $\mathrm{U}$, Jalonen J, Vigfússon G, Alahuhta S, Lagerkranser M. Nordic guidelines for neuraxial blocks in disturbed haemostasis from the Scandinavian Society of Anaesthesiology and Intensive Care Medicine. Acta Anaesthesiol Scand. 2010;54(1):16-41. https://doi. org/10.1111/j.1399-6576.2009.02089.x

2. Fakherpour A, Ghaem H, Fattahi Z, Zaree S. Maternal and anaesthesiarelated risk factors and incidence of spinal anaesthesia-induced hypotension in elective caesarean section: A multinomial logistic regression. Indian J Anaesth. 2018;62(1):36-46 https://doi. org/10.4103/ija.IJA_416_17

3. Chooi C, Cox JJ, Lumb RS, Middleton P, Chemali M, Emmett RS, et al. Techniques for preventing hypotension during spinal anaesthesia for caesarean section. Cochrane Database Syst Rev. 2017;8(8) https:// doi.org/10.1002/14651858.CD002251. pub3

4. Campagna JA, Carter C. Clinical relevance of the Bezold-Jarisch reflex. Anesthesiology. 2003;98(5):125060. Epub 2003/04/30. https://doi. org/10.1097/00000542-20030500000030

5. Liu SS, McDonald SB. Current issues in spinal anesthesia. Anesthesiology. 2001;94(5):888-906. Epub 2001/06/05 https://doi.org/10.1097/00000542200105000-00030

6. Mackey David C, M.D., Carpenter
Randall L, M.D., Tho,pson Gale E, M.D., Brown David L, M.D., Bodily Mark N, M.D. Bradycardia and Asystole during Spinal Anesthesia: A Report of Three Cases Without Morbidity. Anesthesiology: The Journal of the American Society of Anesthesiologists. 1989;70(5):8668. https://doi.org/10.1097/00000542198905000-00026

7. Veelken R, Hilgers KF, Leonard M, Scrogin K, Ruhe J, Mann JF, et al. A highly selective cardiorenal serotonergic 5-HT3-mediated reflex in rats. The American journal of physiology. 1993;264(6 Pt 2):H1871-7 h t t p s://d oi .org / 10.1152 / ajpheart.1993.264.6.H1871

8. Villalón CM, Centurión D. Cardiovascular responses produced by 5-hydroxytriptamine:a pharmacological update on the receptors/mechanisms involved and therapeutic implications. Naunyn-Schmiedeberg's archives of pharmacology. 2007;376(1-2):45-63 https://doi.org/10.1007/s00210-0070179-1

9. Villalón $\mathrm{CM}$, de Vries P, Saxena PR. Serotonin receptors as cardiovascular targets. Drug Discovery Today. 1997;2(7):294-300 https://doi.org/10.1016/S13596446(97)01055-6

10. Yamano M, Kamato T, Nishida A, Ito $\mathrm{H}$, Yuki $\mathrm{H}$, Tsutsumi R, et al. Serotonin (5-HT)3-receptor antagonism of 4, 5, 6, 7 -tetrahyd robenzimidazole derivatives against 5-HT-induced bradycardia in anesthetized rats. 
Japanese journal of pharmacology. 1994;65(3):241-8. https://doi.org/10.1016/ S0021-5198(19)35755-5

11. Sahoo T, SenDasgupta C, Goswami A, Hazra A. Reduction in spinal-induced hypotension with ondansetron in parturients undergoing caesarean section: a double-blind randomised, placebo-controlled study. International journal of obstetric anesthesia. 2012;21(1):24-8. https://doi.org/10.1016/j. ijoa.2011.08.002

12. Bromage PR. A comparison of the hydrochloride and carbon dioxide salts of lidocaine and prilocaine in epidural analgesia. Acta anaesthesiologica Scandinavica Supplementum. 1965;16:55-69. https://doi. org/10.1111/j.1399-6576.1965.tb00523.x

13. Breen TW, Shapiro T, Glass B, FosterPayne D, Oriol NE. Epidural anesthesia for labor in an ambulatory patient. Anesthesia and analgesia.1993;77(5):91924 https://doi.org/10.1213/00000539199311000-00008

14. Marashi SM, Soltani-Omid S, Soltani Mohammadi S, Aghajani Y, Movafegh A. Comparing Two Different Doses of Intravenous Ondansetron With Placebo on Attenuation of Spinalinduced Hypotension and Shivering. Anesthesiology and pain medicine. 2014;4(2):e12055. Epub 2014/05/03 https://doi.org/10.5812/aapm.12055

15. Potdar M, Kamat L, Jha T, Talnikar A, Mahevi Z, Save M. Effect of ondansetron in attenuation of post-spinal hypotension in caesarean section: A comparison of two different doses with placebo.
Journal of Obstetric Anaesthesia and Critical Care. 2017;7(2):69-74. https:// doi.org/10.4103/joacc.JOACC_7_16

16. Tatikonda CM, Rajappa GC, Rath P, Abbas M, Madhapura VS, Gopal NV. Effect of Intravenous Ondansetron on SpinalAnesthesia-Induced Hypotension and Bradycardia: A Randomized Controlled Double-Blinded Study. Anesth Essays Res. 2019;13(2):340-6. https://doi.org/10.4103/aer.AER_22_19

17. El Khouly NI, Meligy AM. Randomized controlled trial comparing ondansetron and placebo for the reduction of spinal anesthesia-induced hypotension during elective cesarean delivery in Egypt. International journal of gynaecology and obstetrics: the official organ of the International Federation of Gynaecology and Obstetrics. 2016;135(2):205-9. https:// doi.org/10.1016/j.ijgo.2016.06.012

18. Trabelsi W, Romdhani C, Elaskri H. Effect of Ondansetron on the Occurrence of Hypotension and on Neonatal Parameters during Spinal Anesthesia for Elective Caesarean Section: A Prospective, Randomized, Controlled, Double-Blind Study. 2015;2015:158061 https://doi.org/10.1155/2015/158061

19. Wang $M$, Zhuo L, Wang Q, Shen M-K, Yu Y-Y, Yu J-J, et al. Efficacy of prophylactic intravenous ondansetron on the prevention of hypotension during cesarean delivery: a dosedependent study. Int J Clin Exp Med. 2014;7(12):5210-6. https://pubmed.ncbi. nlm.nih.gov/25664023/

20. Ortiz-Gómez JR, Palacio-Abizanda 
FJ, Morillas-Ramirez F, Fornet-Ruiz I, Lorenzo-Jiménez A, Bermejo-Albares ML.Theeffectofintravenousondansetron on maternal haemodynamics during elective caesarean delivery under spinal anaesthesia: a double-blind, randomised, placebo-controlled trial. International journal of obstetric anesthesia.2014;23(2):138-43. https://doi. org/10.1016/j.ijoa.2014.01.005
21. Terkawi AS, Tiouririne M, Mehta SH, Hackworth JM, Tsang S, Durieux ME. Ondansetron Does Not Attenuate Hemodynamic Changes in Patients Undergoing Elective Cesarean Delivery Using Subarachnoid Anesthesia: A Double-Blind, Placebo-Controlled, Randomized Trial. Regional anesthesia and pain medicine. 2015;40(4):3448 https://doi.org/10.1097/ AAP.0000000000000274

Citation: Devkota K, Adhikari K, Pradhan B. Effect of Intravenous Ondansetron for Prevention of Spinal Anaesthesia Induced Hypotension During Caesarean Section. JCMS Nepal. 2021 ; 17(4); 289-97. 